\title{
Precoded SLM and PTS Scheme for Reduced PAPR in OFDM for Wireless Communications
}

\author{
Malleswari Akurati \\ Assistant Professor, CVR College of Engineering, Hyderabad \& Research Scholar, JNTUK, \\ Kakinada, India.Malli.akurati@gmail.com \\ Satish Kumar Pentamsetty \\ Department of ECE, ACE Engineering College, Hyderabad, India.
}

Satya Prasad Kodati

Retired Professor, ECE, JNTUK, Kakinada, India.

\begin{abstract}
----
Orthogonal Frequency Division Multiplexing (OFDM) contribute high data rates in current as well as future wireless communication systems but it aches from high Peak to Average Power Ratio (PAPR). But this high PAPR makes the High-Power Amplifier (HPA) complex which increases the cost of it and leads to the drawbacks like Inter Carrier Interference (ICI) and rise in out of band radiation. Even though many techniques are there to decrease the complexity of HPA by reducing the PAPR, Selected Mapping (SLM) and the Partial Transmit Sequence (PTS) provides less PAPR with low complexity. In this paper, both PTS and SLM are combined with Discrete Sine Transform (DST) and their PAPR and efficiencies are also compared with OFDM signal. The proposed hybrid DST-PTS and DST-SLM provides less PAPR compared to OFDM, SLM and PTS techniques with low complexity. Also, the bit error rate for DST-SLM and DST-PTS techniques are compared for different values of SNR. In future wireless communication systems, these proposed techniques can be used as they provide less bit error rate and less PAPR with low complexity.
\end{abstract}

\section{Keywords - OFDM, PAPR, PTS, SLM, DST}

\section{INTRODUCTION}

These days, the ever-increasing technology demanding high data rates in wireless communication systems. To meet this requirement, the OFDM multi carrier modulation technique is used which offers an extortionate spectral efficiency [1]. OFDM provides reduced system complexity as many complex signals are connected by using the Quadrature Amplitude Modulation (QAM) / Quadrature Phase Shift Keying (QPSK) modulation techniques. OFDM is suitable for the standards like Third Generation Partnership Program Long-Term Evolution (3GPP-LTE), LTE-Advanced, Long-Term Evolution (LTE) and the standards such as Digital Subscriber Line (DSL) [2]. But the crucial problem of high PAPR in OFDM deteriorates the performance of HPA and makes the HPA expensive. Researchers provided a massive number of PAPR reduction techniques like precoding, companding and probabilistic approaches like 
PTS and SLM. An outrageous PAPR leads to indigent utilization of power efficiency and the distortions like In and Out-of-Band (I/OOB). Precoding methods reduce the PAPR with less distortion as it boosts the diversity gain [3-4]. In this paper, the DST precoding is combined with PTS and SLM and their performances are compared with OFDM signal. The paper is organized as: Section II gives the detailed explanation of OFDM and its PAPR. Section III presents the hybrid methods (DST-PTS \& DST-SLM) proposed in this paper. Finally, section IV furnish the results and discussion and section $\mathrm{V}$ shows the conclusion of the paper.

\section{OFDM AND PAPR}

\section{A. $O F D M$}

Multiple number of sub carriers are used to produce the OFDM signal which turns the wideband into narrow sub-bands with the over sampling factor of $\mathrm{L}$ is defined by:

$$
\begin{aligned}
x(n) & =\frac{1}{\sqrt{K}} \sum_{k=0}^{K-1} X(k) e^{j 2 \pi} \frac{k}{K} n \\
\text { Where, } n & =0,1, \ldots \ldots \ldots K-1
\end{aligned}
$$

B. PAPR

As it is difficult to compute the PAPR of OFDM signal in continues time domain, it can be expressed in time domain as:

$$
\operatorname{PAPR}(x[n])=\max _{0 \leq n \leq N-1} \frac{|x[n]|^{2}}{E\left[|(n)|^{2}\right]}
$$

The Cumulative Distribution Function (CDF) of a random variable $\mathrm{z}$ is given by:

$$
F(z)=1-\exp (Z)
$$

The Complementary Cumulative Distribution Function (CCDF) which outstrips the threshold point is specified as [5-6]:

$$
F_{z}(z)=1-\left(1-e^{-z}\right)^{n}
$$

\section{PROPOSED HYBRID METHODS}

\section{DST-PTS OFDM system:}

This system gives the combination of PTS technique with DST precoding scheme. PTS technique comes under scrambling technique in which the codes scrabble the codes to diminish the PAPR significantly. But the complexity of PAPR increases with a greater number of IFFTs, hence in the proposed method the smaller number of IFFTS are considered. In scrambling techniques, the entire data unit has been splitted into different sub-blocks. After that, the smallest PAPR is chosen as transmitted signal after the non-overlapping sub blocks are revolved into the independent rotation factors [7].

Figure1 illustrates the mapper circuit which is also called a modulator circuit whose output is converted into a parallel form with the help of a serial to parallel converter. The partition block divides the whole data block into subunits, and they are applied to a precoder circuit. The precoded signal is fed to PTS reduction technique which make use of phase factors to reduce PAPR [8]. 


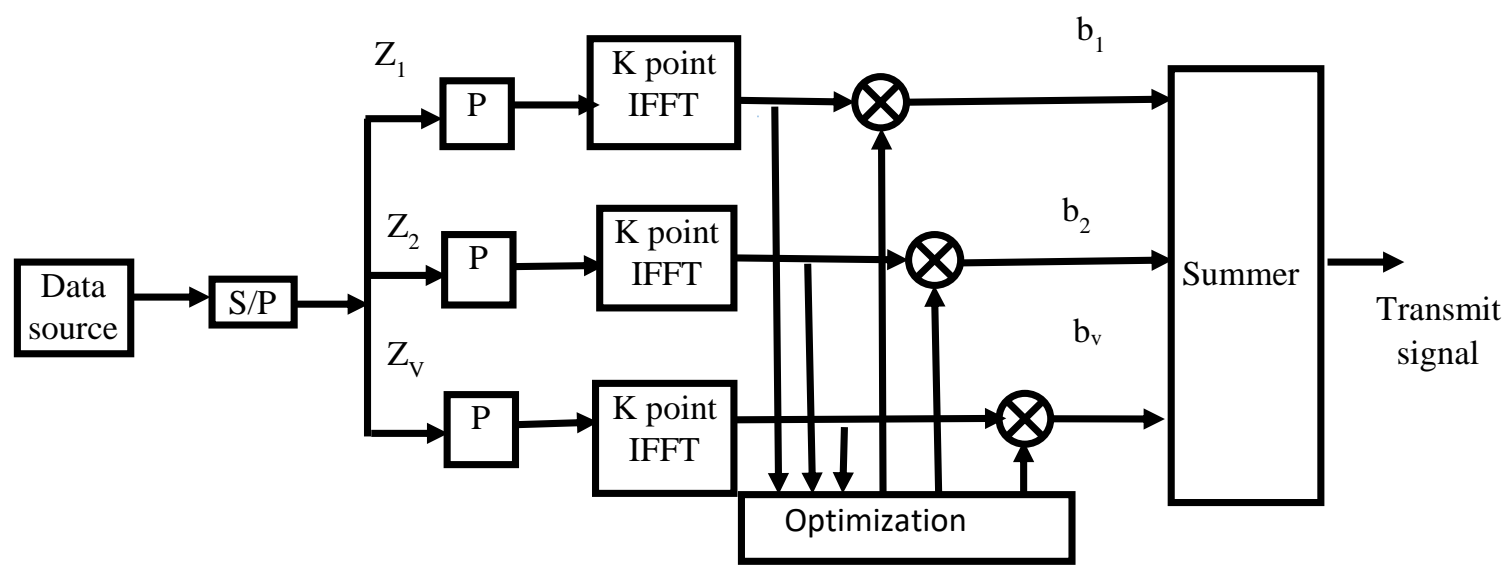

Figure 1. Block diagram of proposed DST-PTS method

Let the input signal as $\mathrm{x}_{\mathrm{n}}$, the equation of DST is indicated as:

$$
Z(k)=\sum_{n=0}^{N-1} x n \cos \left[\frac{\pi}{N+1}\right](n+1)(k+1)
$$

Where $\mathrm{k}=1,2-----------\mathrm{N}-1$.

The precoding matrix of DST is:

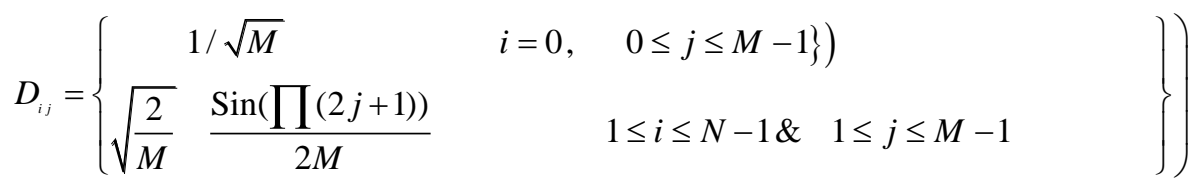

The DST precoding matrix should be of non-singular matrix with the magnitude $\frac{1}{\sqrt{M}}$ and also the elements should have same magnitude [9].

The DST precoded signal is fed to the PTS reduction technique and the transmitted signal is generated as follows [10-11]:

Let the data block $Z=\left[Z_{0}, Z_{1} \ldots \ldots Z_{v-1}\right]$ with its IFFT representation is given by:

$$
z=\left[z_{0}, z_{1-------z_{v-1}}\right]^{T}
$$

The phase factors are indicates as: $W n=e^{j \Phi \pi} n$

Where, $n=0,1-------v-1$.

The combination of rotated phase factors after the adder block is given by:

$$
z=\sum_{n=0}^{v-1} W n z n
$$

\section{DST-SLM OFDM system:}

Figure 2 represents the DST-SLM precoding system. The corresponding data bits are reproduced by multiplying them with $\mathrm{M}$ number of phase vectors. These individual blocks are precoded by DST precoding followed by OFDM modulation [12-13]. Finally, among them, the minor value of PAPR is selected and sent for transmission. 


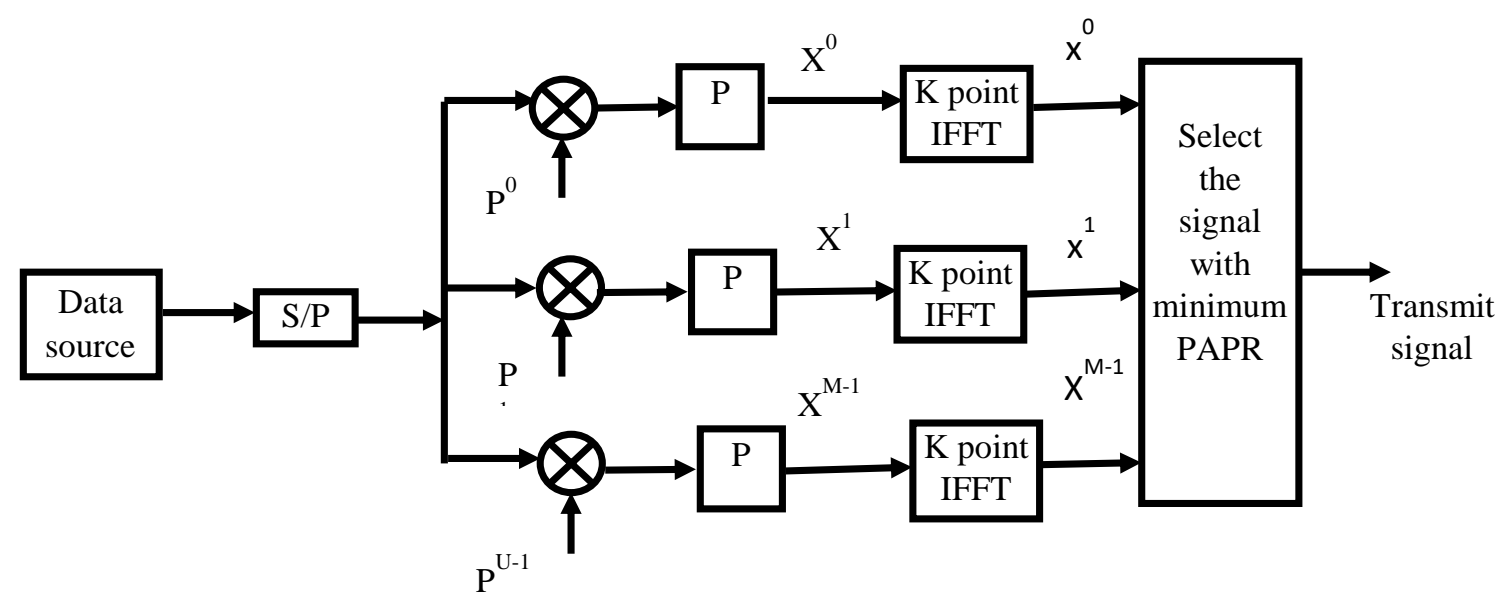

Figure 2. Block diagram of DST-SLM Method

In the process of SLM, an individual data block is defined as: $X=[X 0, X 1, \ldots . X k-1]^{T}$ and it is multiplied by rotation factor M. $P u=[P u 0, P u 1, \ldots \ldots \ldots P u k-1]^{T}$, which indicates the phase factors that are used in SLM method [14-16]. Finally, M sequences that are generated are: $X u=$ $[X u 1, X u 2, \ldots . . X u k-1]$.

\section{RESULTS AND DISCUSSION}

In the proposed method, the precoded OFDM signal is fed to the scrambling techniques like SLM and PTS and their PAPR is calculated. When two or more reduction techniques are combined, they ae called as hybrid techniques and they have several advantages such as better PAPR reduction and low complexity. When the PAPR of hybrid methods are compared with original OFDM, PTS and SLM techniques, their PAPR is reduced by a considerable amount. The number of symbols used are 1024 with 256 sub carriers and the size of QAM is 64 . The following figures shows the DST-PTS and DST-SLM for the sub carriers 256 and 128. Both the techniques give a much better PAPR and provide less system complexity.

$$
\begin{aligned}
& P A P R \text { reduction of OFDM signal }=P A P R \text { before reduction }- \text { Modified PAPR } \\
& \text { Reduction Efficiency }=\frac{\text { Amount of } P A P R \text { reduction }}{\text { Original OFDM PAPR }} \\
& \text { PTS PAPR Reduction }=\text { PTS PAPR }- \text { DST precoded PAPR } \\
& \text { Reduction Efficiency }=\frac{P A P R \text { reduction of OFDM signal }}{P T S P A P R \text { Reduction }} \\
& \text { SLM PAPR Reduction }=S L M P A P R-D S T \text { precoded PAPR } \\
& \text { Reduction Efficiency }=\frac{P A P R \text { reduction of OFDM signal }}{S L M P A P R \text { Reduction }}
\end{aligned}
$$

The following table shows the PAPR efficiencies of PTS and SLM techniques and the hybrid methods like DST-PTS and DST-SLM. As shown in Table I, the PAPR efficiency of PTS technique is $26.4 \%$, SLM is $13.7 \%$, DST-PTS technique $47 \%$ and DST-SLM is $52.9 \%$. The efficiency of proposed DST-PTS is $47 \%$ and DST-SLM is $52.9 \%$ respectively. 
TABLE I. PAPR \& EFFICIENCY OF PTS, SLM \& PROPOSED TECHNIQUES

\begin{tabular}{|l|c|}
\hline Technique & $\begin{array}{l}\text { Value at CCDF=10 } \\
\mathbf{2}\end{array}$ \\
\hline OFDM PAPR & 10.2 \\
\hline OFDM PTS PAPR & 7.5 \\
\hline OFDM PTS PAPR Efficiency & $26.4 \%$ \\
\hline OFDM SLM PAPR & 8.8 \\
\hline OFDM SLM PAPR Efficiency & $13.7 \%$ \\
\hline DST -PTS OFDM PAPR PAPR & 5.4 \\
\hline $\begin{array}{l}\text { DST-PTS OFDM PAPR } \\
\text { Efficiency }\end{array}$ & $47 \%$ \\
\hline DST -SLM OFDM PAPR & 4.8 \\
\hline $\begin{array}{l}\text { DST -SLM OFDM PAPR } \\
\text { Efficiency }\end{array}$ & $52.9 \%$ \\
\hline
\end{tabular}

The simulation results are shown in the following figures. Figure 3 gives the PAPR calculation of OFDM, OFDM-PTS and DST-PTS OFDM techniques. The PAPR of OFDM is compared with the PTS and DST-PTS OFDM techniques for the number of sub carriers $\mathrm{N}=$ 256 with the number of symbols 1024. In all cases, the PAPR has been evaluated at CCDF equal to $10^{-2}$. As shown in Table II, the PAPR of original OFDM is 10.4, PTS technique's PAPR is 7.5 and DST-PTS technique is 5.4. When the PTS and hybrid DST-PTS are compared to original OFDM signal, their PAPR is reduced by a great amount. PTS technique improves the PAPR reduction by $2.9 \mathrm{~dB}$ compared to original OFDM and DST-PTS technique improves the PAPR by $5 \mathrm{~dB}$ compared to OFDM signal and $2.9 \mathrm{~dB}$ compared to PTS reduction technique.

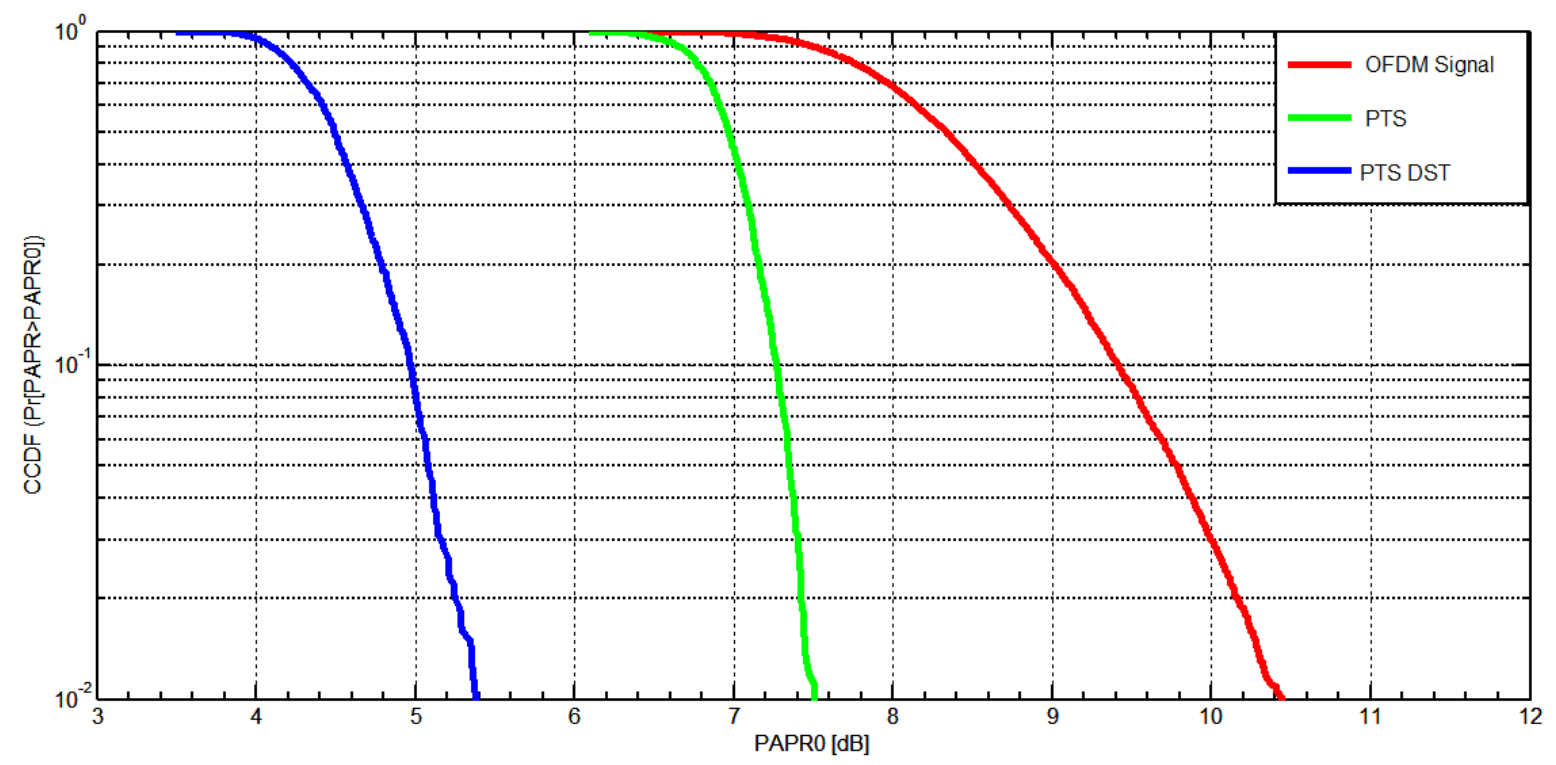

Figure 3. Comparison of OFDM, OFDM-PTS and DST-PTS OFDM for N=256 
TABLE II. ANALYSIS OF OFDM WITH DST-PTS TECHNIQUE

\begin{tabular}{|l|c|}
\hline Method & PAPR (dB) at CCDF $=\mathbf{1 0}^{-2}$ \\
\hline OFDM & 10.4 \\
\hline OFDM with PTS & 7.5 \\
\hline DST-PTS OFDM & 5.4 \\
\hline
\end{tabular}

Figure 4 gives the PAPR calculation of OFDM, OFDM-SLM and DST-SLM OFDM techniques. The PAPR of OFDM is compared with the SLM and DST-SLM OFDM techniques for the number of sub carriers $\mathrm{N}=256$ with the number of symbols 1024 . As shown in Table III, the PAPR of original OFDM is 10.6 , SLM technique's PAPR is 9.3 for $\mathrm{M}=2$ and 8.7 for $\mathrm{M}=4$. The DST-SLM technique's PAPR is 5.2 for $\mathrm{M}=2$ and 4.9 for $\mathrm{M}=4$. The proposed DST-SLM technique reduces the PAPR by $5.4 \mathrm{~dB}$ for $\mathrm{M}=2$ and by $5.7 \mathrm{~dB}$ for $\mathrm{M}=4$ compared to original OFDM.

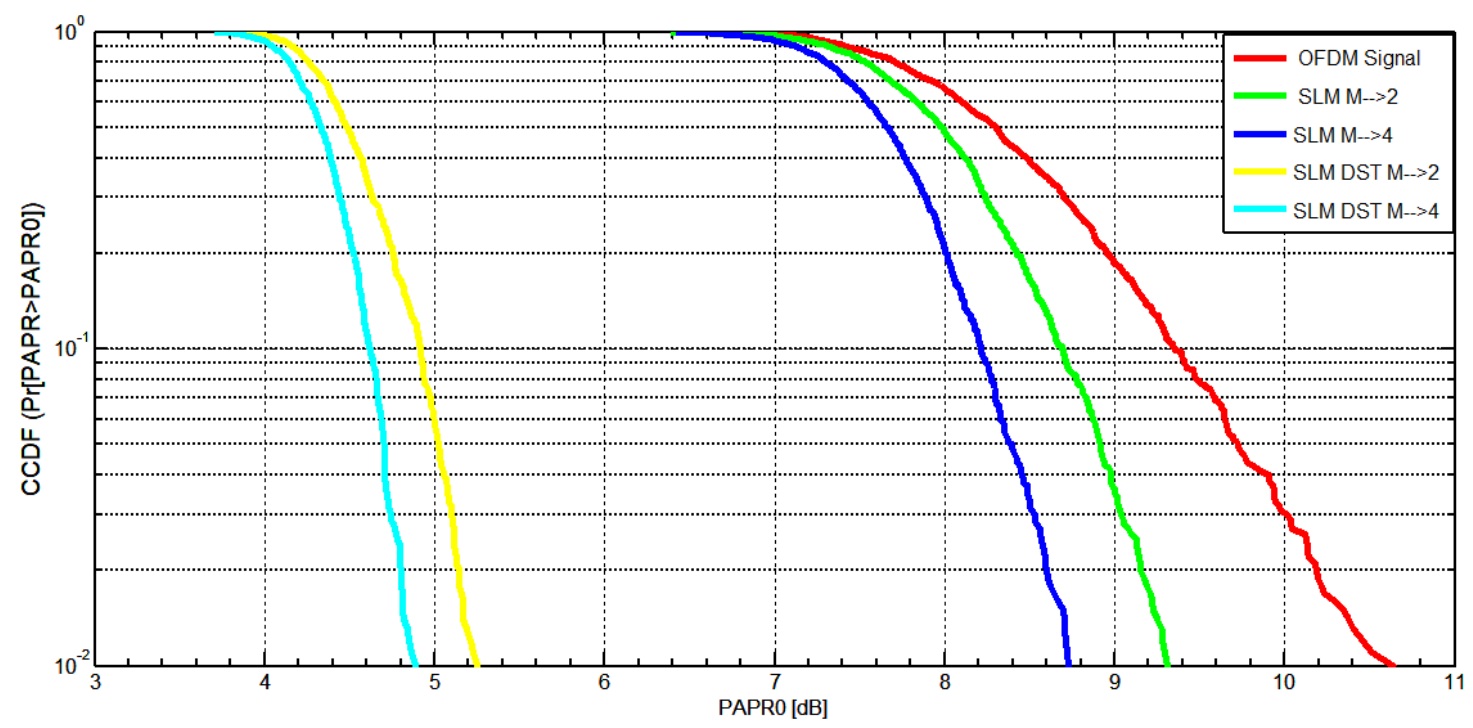

Figure 4. Comparison of OFDM, OFDM-SLM and DST-SLM OFDM for N=256

TABLE III. ANALYSIS OF OFDM WITH DST-SLM TECHNIQUE

\begin{tabular}{|l|c|}
\hline Method & $\begin{array}{l}\text { PAPR }(\mathbf{d B}) \text { at CCDF }=\mathbf{1 0}^{-} \\
\mathbf{2}\end{array}$ \\
\hline OFDM & 10.6 \\
\hline $\begin{array}{l}\text { OFDM with SLM for M }= \\
2\end{array}$ & 9.3 \\
\hline $\begin{array}{l}\text { OFDM with SLM for M }= \\
4\end{array}$ & 8.7 \\
\hline $\begin{array}{l}\text { DST-SLM OFDM for M }= \\
2\end{array}$ & 5.2 \\
\hline $\begin{array}{l}\text { DST-SLM OFDM for M }= \\
4\end{array}$ & 4.9 \\
\hline
\end{tabular}


Figure 5 gives the PAPR calculation of OFDM, OFDM-PTS and DST-PTS OFDM techniques for the number of sub carriers $\mathrm{N}=128$ with the number of symbols 1024 with the CCDF equal to $10^{-2}$. As shown in Table IV, the PAPR of original OFDM is 10.2, PTS technique's PAPR is $6.9 \mathrm{~dB}$ and DST-PTS technique is 5.1. Compared to 256 sub carriers, 128 carriers reduce the PAPR by $0.3 \mathrm{~dB}$.

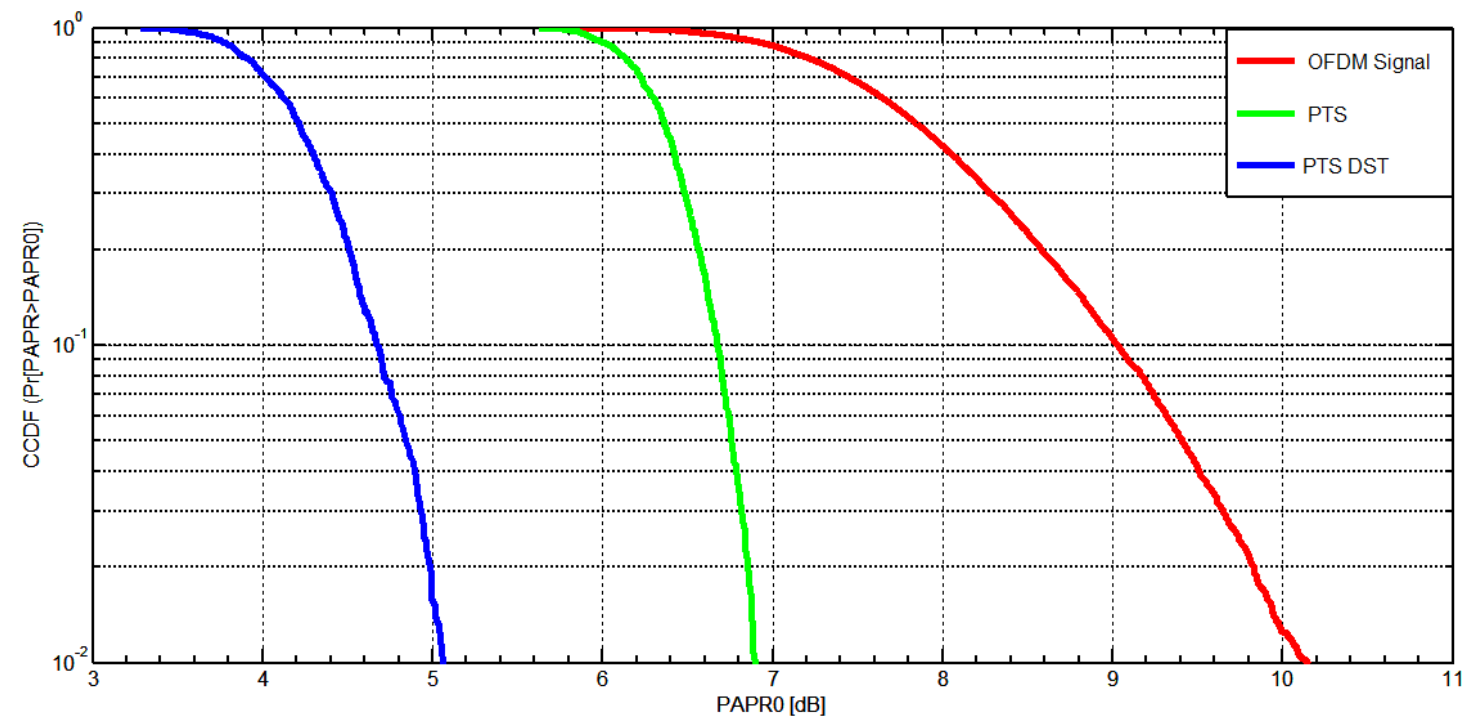

Figure 5. Comparison of OFDM, OFDM-SLM and DST-SLM OFDM for N=128

TABLE IV. ANALYSIS OF OFDM WITH DST-PTS TECHNIQUE

\begin{tabular}{|l|c|}
\hline Method & PAPR $(\mathbf{d B})$ at $\mathbf{C C D F}=\mathbf{1 0}^{-\mathbf{2}}$ \\
\hline OFDM & 10.2 \\
\hline OFDM with PTS & 6.9 \\
\hline DST-PTS OFDM & 5.1 \\
\hline
\end{tabular}

Figure 6 shows the bit error rate performance of DST-PTS. Compared to conventional PTS, the DST-PTS scheme provides less bit error rate for the lesser value of signal to ratio. As shown in the figure, the hybrid DST-PTS provides less BER compared to PTS and OFDM techniques for the same signal to noise ratio. 


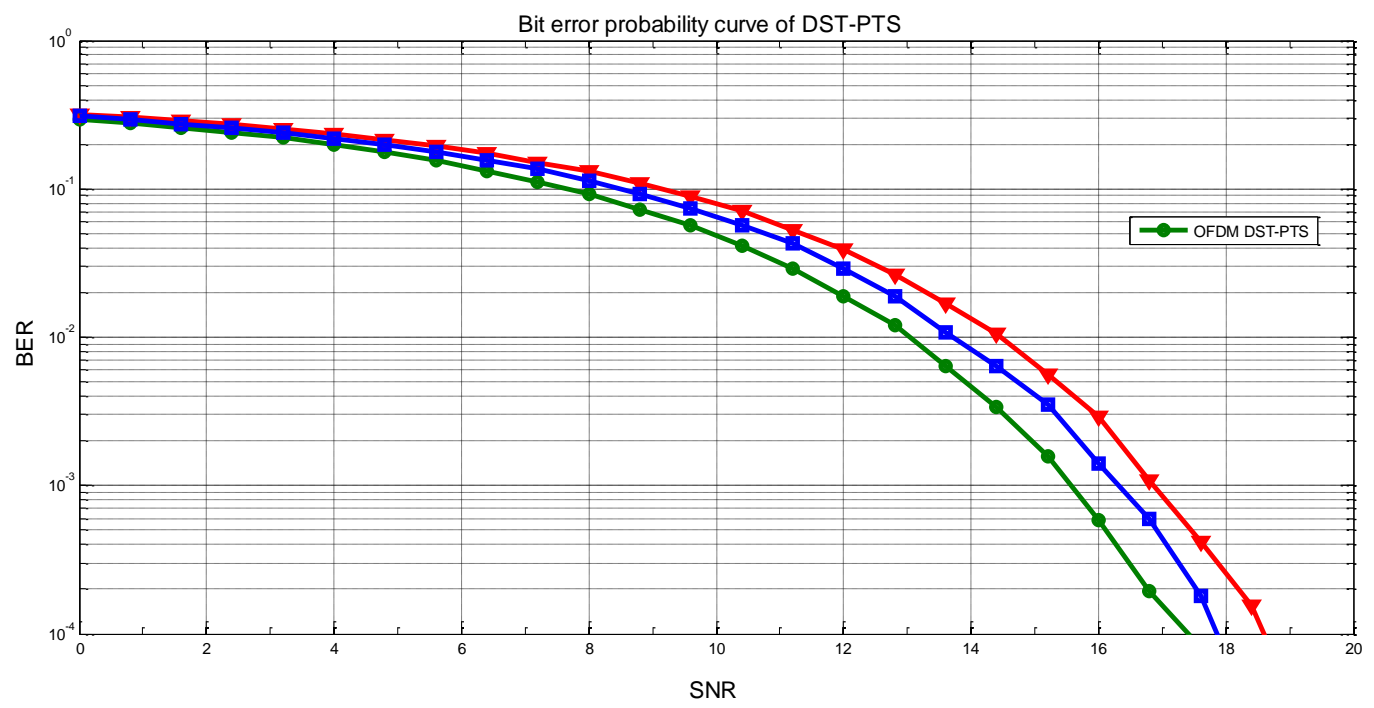

Figure 6. Performance of DST-PTS compared to PTS \& OFDM

Figure 7 gives the PAPR calculation of OFDM, OFDM-PTS and DST-PTS OFDM techniques for the number of sub carriers $N=128$. As shown in Table V, the PAPR of original OFDM is $9.9 \mathrm{~dB}$, SLM technique's PAPR is $8.2 \mathrm{~dB}$ and DST-PTS technique is 4.6. Compared to 256 sub carriers, 128 carriers reduces the PAPR by $0.3 \mathrm{~dB}$.

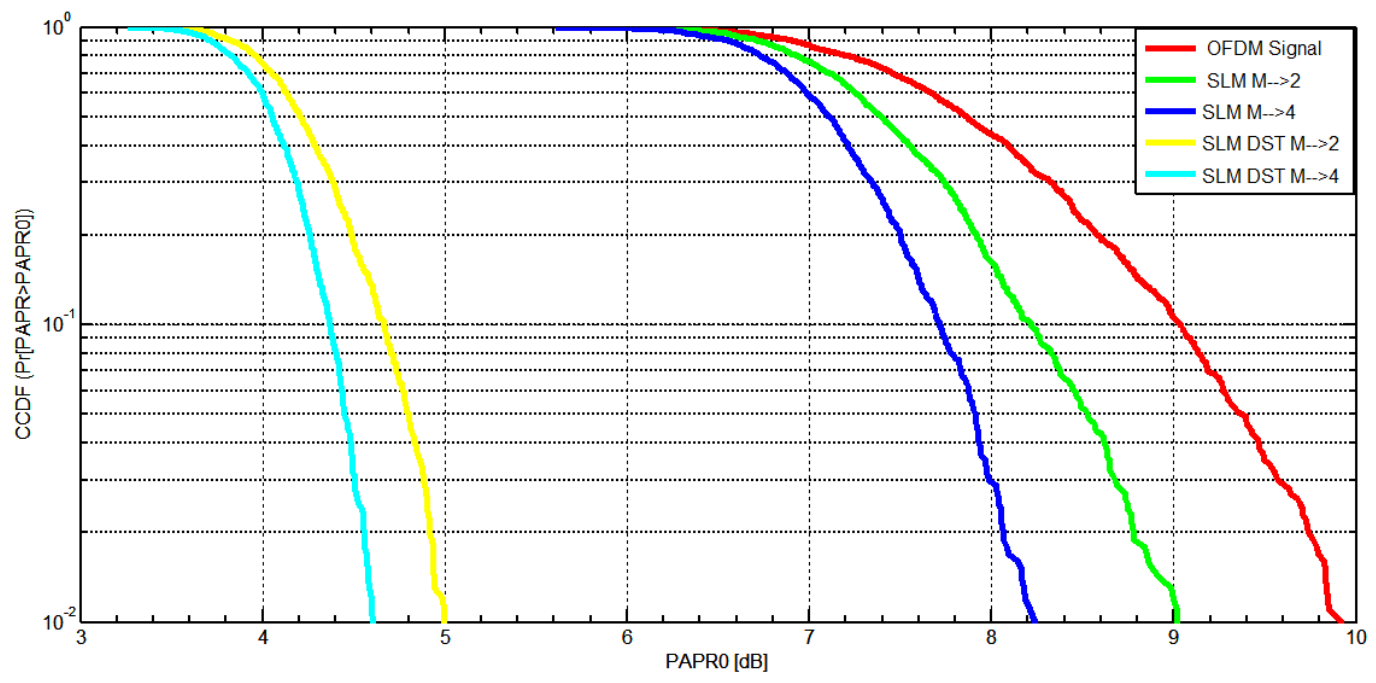

Figure 7. Comparison of OFDM, OFDM-SLM and DST-SLM OFDM for N=128

TABLE V. ANALYSIS OF OFDM WITH DST-PTS TECHNIQUE

\begin{tabular}{|l|c|}
\hline Method & PAPR (dB) at CCDF $=\mathbf{1 0}^{-2}$ \\
\hline OFDM & 9.9 \\
\hline $\begin{array}{l}\text { OFDM with SLM for M }= \\
2\end{array}$ & 9 \\
\hline $\begin{array}{l}\text { OFDM with SLM for M }= \\
4\end{array}$ & 8.2 \\
\hline $\begin{array}{l}\text { DST-SLM OFDM for M }= \\
2\end{array}$ & 5 \\
\hline
\end{tabular}




\begin{tabular}{|l|c|}
\hline Method & PAPR $(\mathbf{d B})$ at $\mathbf{C C D F}=\mathbf{1 0}^{-2}$ \\
\hline $\begin{array}{l}\text { DST-SLM OFDM for } \mathrm{M}= \\
4\end{array}$ & 4.6 \\
\hline
\end{tabular}

Figure 8 shows the bit error rate performance of DST-SLM. Compared to SLM, the DST-SLM scheme provides less bit error rate for the lesser value of signal to ratio. Compared to OFDM and SLM, DST-SLM provides less bit error rate. Also when compared to DST-PTS, DST-SLM provides less bit error rate. But both the proposed techniques DST-PTS and DST-SLM provide less BER compared to OFDM, SLM and PTS.

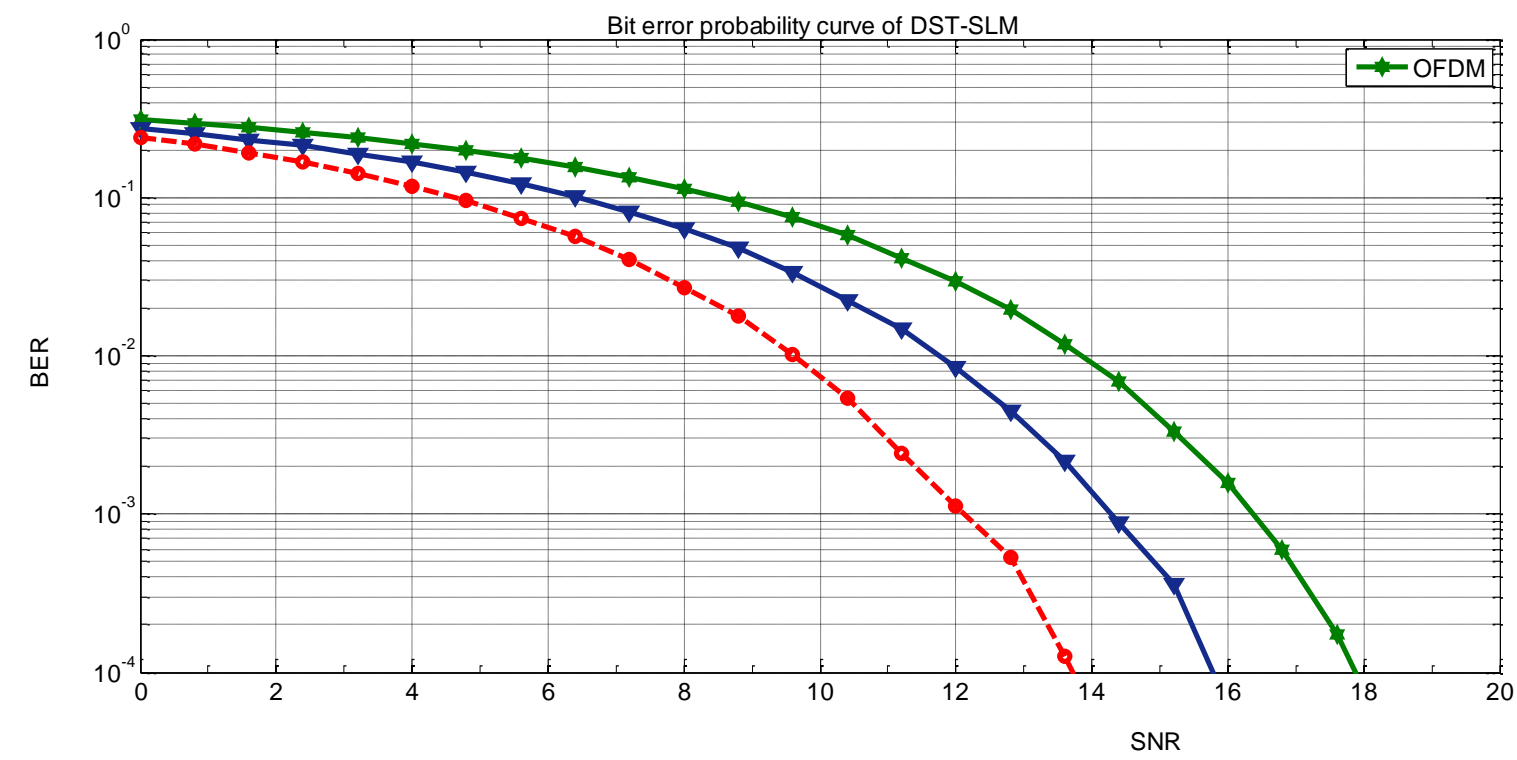

Figure 8. Performance of DST-SLM compared to SLM \& OFDM

\section{CONCLUSIONS}

This document presents a PTS scheme with DST precoding and SLM with DST precoding for the reduction of PAPR and improvement of its efficiency. Both the techniques are compared for the number of subcarriers 256 and 128. In DST-PTS scheme, considering the lesser value of $\mathrm{v}$, reduces the complexity and in DST-SLM scheme, considering $\mathrm{M}=4$ is a good choice as it provides less PAPR. If $\mathrm{M}$ is high, the complexity is increased and if $\mathrm{M}$ is low, PAPR reduction capability is low. Hence, $M$ should be a moderate value. Both the proposed techniques reduce the PAPR by a reasonable amount compared to OFDM and their bit error rates are less. When DST-SLM and DST-PTS are compared, DST-PTS technique's PAPR is $5.4 \mathrm{~dB}$ for $\mathrm{N}=256$ and $4.9 \mathrm{~dB}$ for $\mathrm{N}=128$. Whereas for DST-SLM, PAPR is $5.1 \mathrm{~dB}$ for $\mathrm{N}=256$ and $4.6 \mathrm{~dB}$ for $\mathrm{N}=128$. When compared to DST-PTS scheme, DST-SLM provides low PAPR with the reduction of $0.3 \mathrm{~dB}$. Also, DST-SLM provides less bit error rate compared to DSTPTS and both the techniques provide less bit error rate compared to conventional methods. Hence the proposed techniques are preferred for future wireless systems. 


\section{References}

[1] Y. Wang, J. Xu, and L. Jiang, "Challenges of system-level simulations and performance evaluation for $5 G$ wireless networks" IEEE Access, vol. 2, pp. 1553-1561, 2014, doi: 10.1109/ACCESS.2014.2383833.

[2] H. Yang, "A road to future broadband wireless access: MIMO-OFDM-based air interface", IEEE Communication Magazine, vol. 43, no. 1, pp. 53-60, Jan. 2005, doi: 10.1109/MCOM.2005.1381875.

[3] Y. Huo, X. Dong, and W. Xu, "5G cellular user equipment : From theory to practical hardware design”, IEEE Access, vol. 5, pp. 13992-14010, 2017, doi: 10.1109/ACCESS.2017.2727550.

[4] L. J. Cimini and N. R. Sollenberger, "Peak-to-average power reduction ofan OFDM signal using partial transmit sequences, " in Proc. IEEE ICC,Vancouver, BC, Canada, 1999, pp. 511515.

[5] S. J. Ku, C. L. Wang and C. H. Chen, "A Reduced-Complexity PTS-Based PAPR Reduction Scheme for OFDM Systems," in IEEE Transactions on Wireless Communications, vol. 9, no. 8, pp. 2455-2460, August 2010.

[6] Y. Rahmatallah and S. Mohan, "Peak-To-Average Power Ratio Reduction in OFDM Systems: A Survey and Taxonomy", in IEEE Communications Surveys \& Tutorials, vol. 15, no. 4, pp. 1567-1592, Fourth Quarter 2013

[7] C. L. Wang and Q. Y. Yuan, "Low-complexity Selected Level Mapping schemes for peak-toaverage power ratio reduction in OFDM systems", IEEE Transactions on Signal Processing, vol. 53, no. 12, pp. 4652-4660, December 2005.

[8] R. J. Baxley and G. T. Zhou, "Power savings analysis of peak-to-average power ratio in OFDM', IEEE Transactions on Consumer Electronics, vol. 50, no. 3, pp. 792-798, Aug. 2004, doi: 10.1109/TCE.2004.1341681.

[9] H. B. Jeon, J. S. No, and D. J. Shin, "A low-complexity SLM scheme using additive mapping sequences for PAPR reduction of OFDM signals", IEEE Transactions on Broadcasting, vol. 57, no. 4, pp. 866-875, Dec. 2011, doi: 10.1109/TBC.2011.2151570.

[10] X. Wang, T. T. Tjhung, and $Y$. Wu, "On the SER and spectral analyses of A-law companding multicarrier modulation”, IEEE Vehicular Technology Conference (VTC), vol. 52, pp.14081412, September 2003.

[11]Z. Liu, Y. Xin, and G. B. Giannakis, "Linear constellation precodingfor OFDM with maximum multipath diversity and coding gains, "IEEETrans. Commun., vol. 51, no. 3, pp. 416-427, Mar. 2003.

[12]Imad A. Shaheen,*, Abdelhalim Zekry, Fatma Newagy, Reem Ibrahim, "Performance evaluation of PAPR reduction in FBMC system using nonlinear companding transform", Science direct. ICT Express, Vol.5, Issue 1, Mar.2019, Pages 41-46, doi: 10.1016/j.icte.2018.01.017.

[13] D.Roque, C. Siclet, J. M. Brossier and P. Siohan, "Weighted cyclic prefix OFDM: PAPR analysis and performances comparison with DFT-precoding," 2012 Conference Record of the Forty Sixth Asilomar Conference on Signals, Systems and Computers (ASILOMAR), Pacific Grove, CA, 2012, pp. 1065-1068.

[14] Wang, Z. and Chen, S. (2014) Reduction PAPR of OFDM Signals by Combining Grouped DCT Precoding with PTS. Journal of Signal and Information Processing, 5, 135-142. 
[15] Baig and V. Jeoti, "PAPR analysis of DHT-precoded OFDM system for M-QAM," Intelligent and Advanced Systems (ICIAS), 2010 International Conference on, Kuala Lumpur, Malaysia, 2010, pp. 1-4.

[16] H. Gong, W. Ye, S. Feng, and F. Ke, "A threshold companding scheme for reducing peak-toaverage power ratio of OFDM signals", International Conference on Wireless Communications, Networking and Mobile Computing, vol. 1, September 2005, pp. 573-576. 